\title{
Elimination of Resonant Phenomena Adverse Effect in the Process of Experi- mental Operation of Gears
}

Anna Šmeringaiová (0000-0002-7935-3145)

Technical University of Košice. Faculty of Manufacturing Technology, 08001 Prešov, Bayerova 1, SR, E-mail: anna.smeringaiova@tuke.sk

The paper describes the course, conditions and results of the impact test of the supporting frame of the test station for dynamic tests of gears. The test station makes it possible to simulate different gears operating conditions. The basic support frame structure of the test station was evalu-ated as unsufficient based on the results of measurement and processing of the measured low and high frequency vibration values in the verification series of experimental tests. The basic failure of the original design were the significant resonance actions that were the results of the dominant sources of vibration being near the natural frequencies of the vertical and horizontal beams of the test station base. A structural design of the test station supporting frame was designed and implemented. The goal was to increase the rigidity of the frame and eliminate unwanted resonance phenomena. The impact tests were used to determine the values of the natural frequencies of the most stressed parts of the supporting structure - vertical and horizontal beams, before and after implementation of struc-tural modifications. The comparability of the impact test results was determined by adherence to identical measurement conditions.

Keywords: Test Station, Dynamic Tests, Gears, Natural Frequencies, Impact Test

\section{Introduction}

Gearing, as the most common transmission mechanism in a machine unit representing a dynamic system, is often a crucial element that determines the dynamic properties of the entire system. In real applications the dynamic properties and behavior of gears in the field of power and kinematic transmissions does not have an ideal character defined only by the gear ratio. The nature of a particular transmission mechanism is determined by a number of factors. Especially in transient states, with improperly selected gearbox parameters, there can be a great dynamic stress on their functional parts. When designing transmissions, it is usually that a wide range of required properties like operating parameters, economic characteristics and also environmental ecology will meet. Therefore, universal solutions cannot be expected and it is necessary to look for a specific solution for each specific problem.

At the Department of Technical Systems Design and Monitoring, Faculty of Manufacturing Technologies, Technical University in Košice, a test station was designed and built for the realisation of dynamic tests of gears. The test station makes it possible to simulate different operating conditions and to carry out shortterm as well as long-term comparative tests of different types of gearboxes. It is possible to test, for example, a selected type of gearbox with various design and technological modifications in conditions close to real operation. The aim of frame modifications is to reduce the dynamic load of the functional parts of the transmissions, to improve their parameters and thus increase their service life.

\section{Test station}

The test station in Fig. 1 simulates a work machine. A detailed description and a schematic diagram of the test station are given in [1]. The load on the gearbox from the implement is generated by a weight that moves vertically in a guide protected in both directions (up and down). The operation of the test station is controlled by a frequency converter according to the selected load program. Rotational speed and load can be changed as required. The reverse movement and the continuous operating mode make it possible to monitor the course of wear of the functional parts of the gears and to assess their service life in the accelerated mode.

In addition to our research into the dynamics of gears, other requirements were set during the design and implementation of the test station:

- In the field of research: the possibility of predicting the results of experimental dynamic tests of gears and belt transmissions.

- In the field of education: the use of a test station as a visual teaching aid in the technical mechanics and machine parts teaching process. 
A mathematical model and digital prototype of the test station were created. Based on the mathematical description of the machine given in [1], a block simulation diagram of the dynamic model of the test station formed in the MATLAB computer system. In Simulink, a dynamic model of the test station was created on the basis of its mathematical relations. The next step was to create a block diagram of the model in Simscape, supplemented by blocks that take into account all losses and resistance moments. The individual blocks correspond to the physical elements that form the test station. With the model, it is possible to perform experiments similar to those on a real object. By simulating the operation of the tested gearboxes, it is possible to set the input parameters of the laboratory tests so as to avoid the risk of their damage right at the beginning of the test operation. At the same time, the course of the simulation can be compared with the real parameters measured during the test operation at the test station.
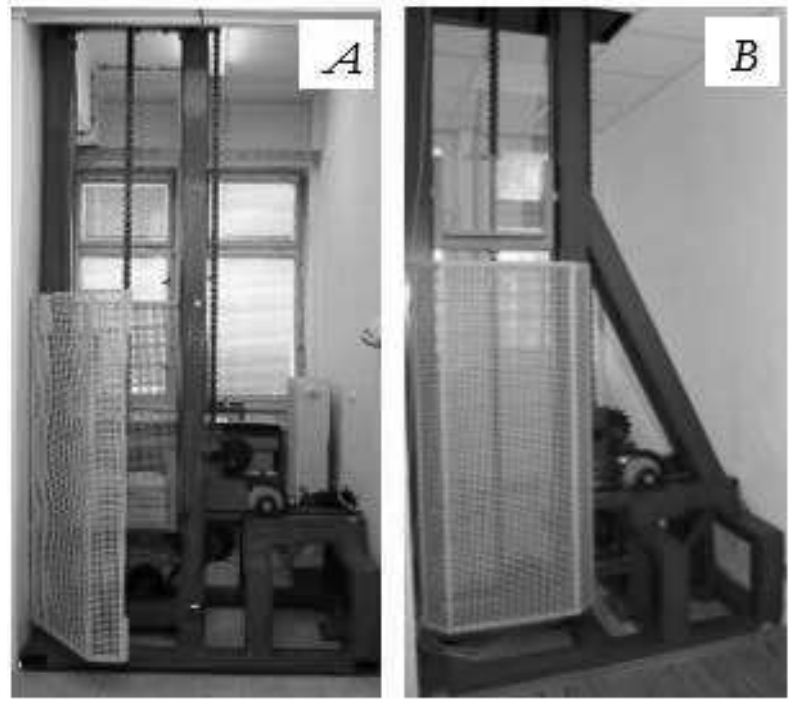

Fig. 1 Test station for dynamic tests of gear $A-$ before and $B$ - after design modification

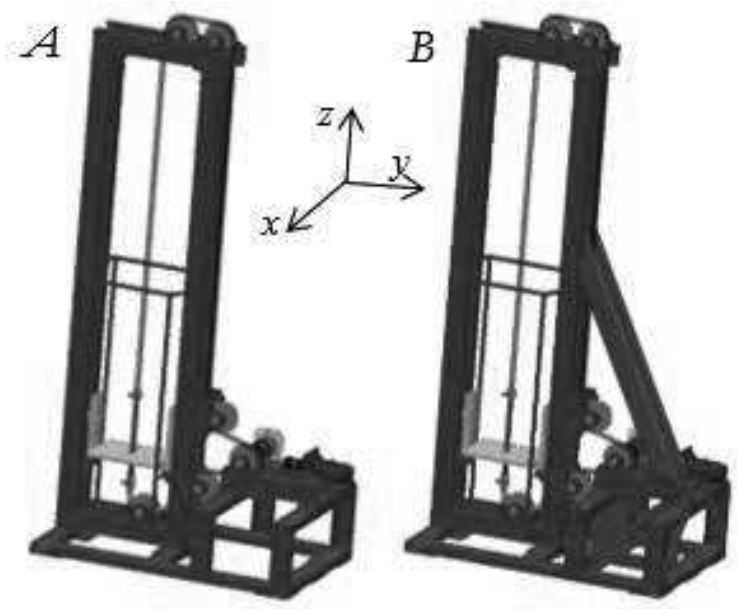

Fig. $23 D$ model test station for dynamic tests of gear $A-$ before and B - after design modification
A digital prototype of a test station for dynamic testing of gear and belt transmissions was created in the Autodesk Inventor Professional graphics systém (see Fig. 2). In the environment for Dynamic simulation, the basic model of the test station was modified to perform various kinematic and dynamic analyses.

\subsection{Functional tests of the test station}

The basic requirement for the functional use of the test station was to obtain objective and comparable results of experiments. This requirement was verified by functional tests. In the first stage of the tests, was tested the correct functioning of the test station, measuring instruments and equipment. The selection of methods for measuring the wear of functional parts of transmissions and diagnostic methods to assess their technical condition were also assessed. Commonly manufactured single-speed helical gearboxes Z80-J010-P were used as the tested object. During the experimental operation, the technical condition of the helical gearboxes was monitored in two different operating modes. According [2] the operating conditions have been designed to achieve a maximum of $70 \div 80$ $\%$ of the nominal power of the gearbox guaranteed by the manufacturer. The following dynamic characteristics of helical gearboxes were measured and evaluated: the size of the load amplitudes and its frequency, the oil temperature, the wear of the helical gear teeth. After the end of the test operation, an impact test was performed to verify the functionality of the stand. A detailed description of the preparation and running of a series of validation experimental measurements is described in [3]

\subsection{Results of verification tests.}

According to [3], based on the results of measurements of dynamic quantities (temperature, vibration, ultrasound), it was found:

- significant difference of measured parameters depending on the load of the gearbox,

- significant changes in the measured parameters during heating, the effect of thermal expansion of helical gear teeth, bearings and chain on the clearence, until the temperature stabilizes,

significant resonant events, high mechanical vibrations above the recommended limit of Alarm 2 - hazard according to [4] (ISO10816-3 Vibration Severity Standard), mainly the vertical beam and the horizontal frame under the sprocket, the transmission of these vibrations to the transmission and a significant deterioration of the engagement conditions on the gear,

- unfavorable operating conditions when starting the engine (gearbox), especially due to 
higher loads, oscillations and insufficient chain guidance, again transmission of vibrations to the gearbox.

The basic supporting structure of the test station was evaluated as unsatisfactory after processing the measured values of low-frequency and high-frequency vibrations in a verification series of experimental tests. The main shortcoming of the original design were significant resonance events. The occurrence of resonant phenomena was due to the fact that the dominant sources of vibration were located near the natural frequencies of the vertical and horizontal beam of the basic structure of the test station.

\section{Resonance as a special fault}

When identifying faults on rotary machines using vibration diagnostics, in addition to common faults, we sometimes encounter a special fault, which is not really a fault. It is resonance or operation at critical speeds. Resonance occurs when the frequency of the excitation force is the same as the natural resonant frequency.

In technical practice, the most common cause of forced oscillations are excitation force effects arising during the operation of machines. According [5], [6], etc. the presence of vibrations adversely affects not only the life cycle and reliability of the machinery, but also the working environment. This is especially true for rotary machines, where generated periodic forces are transmitted to the device itself, but also to its surroundings, e.g. to the basics of the machine. The limiting factor in terms of vibration isolation is most often the amplitude of oscillation. The principle is that the operating mode of machines must be chosen so that the circular frequency of the excitation force is significantly far from the natural circular frequency $\Omega_{0}$, usually in the supra-resonance area $\omega>\Omega_{0}$, because, on the basis of the amplitude characteristic (Fig. $3)$, this is where the amplitude decreases significantly. [7]

The theoretical justification of the course of the resonance curve in Fig. 3 according to [8] results from the motion equation of the forced oscillation of a spring oscillator with parameters $m$ and $k$ (for simplicity, a non-damped oscillator is considered). If a harmonic force acts on the oscilator $F(t)=$ $F_{0} \sin \omega t[N]$ the motion equation of the oscillator has a shape

Where:

$$
m \ddot{x}=-k x+F_{0} \sin \omega t
$$

$m$... Weight of the Body [kg],

$x$...Displacement amplitude [m],

$\ddot{x}$...Acceleration amplitude $\left[\mathrm{m} \cdot \mathrm{s}^{-2}\right]$

$k$...Spring stiffness $\left[\mathrm{N} \cdot \mathrm{m}^{-1}\right]$,

$F_{0} \sin \omega t \ldots$ Excitation force $[\mathrm{N}]$.
With the substitution into the equation (1) $\ddot{x}=$ $-\omega^{2} C \sin \omega_{\max }, x=C \sin \omega_{\max }$ and adjust to the relation for the amplitude of the forced oscillations

$$
C \frac{F_{0}}{m} \frac{1}{\Omega_{0}^{2}-\omega^{2}}[m]_{\max }
$$

Where:

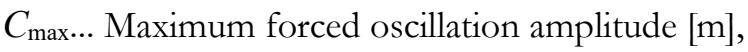
$\omega . .$. Frequency of oscillation $\left[\mathrm{rad} \cdot \mathrm{s}^{-1}\right.$,

$\Omega_{0} \ldots$ Natural angular frequency of free undamped oscillation $\left[\mathrm{rad} \cdot \mathrm{s}^{-1}\right]$, which is defined by the

equation (3):

$$
\Omega_{0}^{2}=\frac{k}{m}\left[\text { rad. } \mathrm{s}^{-1}\right]
$$

It is clear from the result that at $\omega \rightarrow \Omega_{0}$ the amplitude of the forced oscillations increases without restriction $\left(C_{\max } \rightarrow \infty\right)$. This is just a physical abstraction, because every real oscillator is always damped and its resonant curve corresponds more to the curve 1 in Fig. 3. From the graphical representation of the oscillation amplitude as a function of the angular frequency it can be seen that the amplitude of the forced oscillation $C$ with a gradual change in the circular frequency of the excitation force $\omega$ from 0 where it firstly gradually increases, in resonance area, that is near $\omega=\Omega_{0}(\eta=1)$ reaches its highest value and further increases $\omega \rightarrow \infty$ asymptotically approaches zero. It is clear from the graph that the amplitude of the forced oscillations reached the largest value at the frequency of the excitation force, which is almost identical to the frequency of the oscillator's own oscillation $\left(\omega=\Omega_{0}\right)$. In oscillation theory, we call this state resonance and the surrounding environment $\eta=1$ area of resonance. The position of the curve maximum determines the resonant frequency of the oscillator and the damping effect of the system also has a significant effect on the shape of the curve. The sharp maximum is characterized by an oscillator with low damping (curve 1), the oscillator with higher damping has a resonant curve with a less pronounced maximum (curve 2).

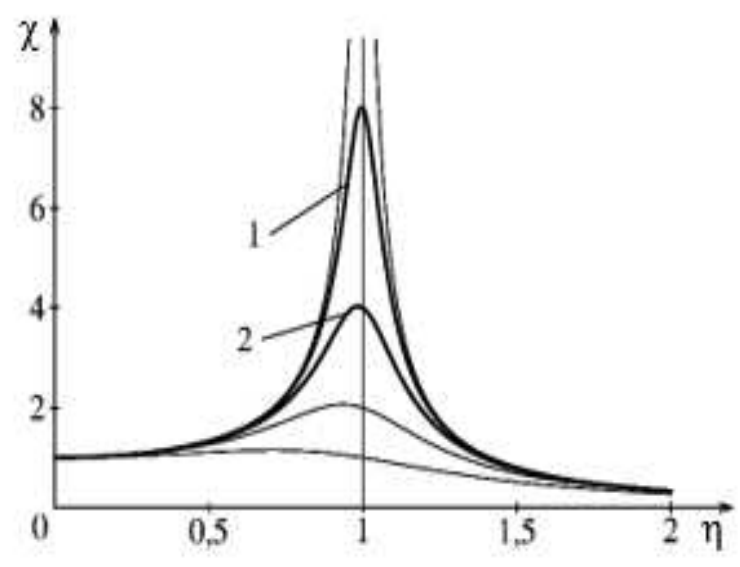

Fig. 3 Resonance curve 
Where $\chi$ is the Dynamic coefficient and $\eta$ is the Frequency ratio defined by the equations

$$
\begin{gathered}
\chi=\frac{c_{\max }}{c_{s t}[-]}, \\
\eta=\frac{\omega}{\Omega_{0}}[-],
\end{gathered}
$$

and $\mathrm{C}_{\mathrm{st}}[\mathrm{m}]$ is amplitude caused by static load of maximum excitation force.

\section{Solving adverse resonance events}

In resonance case, even a small imbalance will cause a high response in the system and high vibrations will occur. In order to be able to eliminate this phenomenon, it is necessary to identify it and precisely determine the natural resonant frequencies. Usually, the natural frequencies are determined by means of a bump test. Several studies offer valuable insights on research and response to adverse resonance events (see in particular [9], [10], [11], [12], [13] and [14]).

In general, there are two ways to deal with resonant phenomena:

- changing the frequency of the driving force, (engine shaft revolutions),

- tuning the system, that means moving the resonant band to a frequency range where there is no excitation.

Generally for resonant frequency $f$ r:

$$
f_{r}=\frac{1}{2 \pi} \sqrt{\frac{k}{m}}[H z],
$$

From the equation (6) with increasing stiffness $(k)$ the resonant frequency increases (shifts upwards), and with increasing mass $(m)$ the resonant frequency decreases (shifts downwards).

In the case of the test station, alternative - optimization of the structure of the supporting frame was chosen for the solution of resonant phenomena. The aim of the measures is to increase the rigidity of the basic structure of the test station. Reinforcement of the frame, securing of the chain guide and sufficient fastening of the weights should have a positive effect on the elimination of vibrations and the displacement of the resonant band of the basic structure outside the frequency range of the excitation forces.

A design of structural modifications of the test station supporting frame was prepared. Fig. 1 shows a 3D model of the original test station and a modified version. After the real test station frame was reinforced, an impact test was repeated. By measuring and comparing the natural frequencies of the test station basic structure before and after the design modification, the fulfillment of the expected goal was checked.

\section{Impact test}

The natural frequencies of the mechanical system were determined by the bump test of the mechanical system:

- Before design of the test station, after completion of the functional tests described in [3].

- After modification of the test station frame support design.

The impact test was performed at rest state of the mechanical system. The values of the natural frequencies of the supporting structure most stressed parts (vertical and horizontal beam) and the tested helical gearbox were measured. The condition for the comparability of the results of the impact test was the observance of identical conditions during the measurement.

\subsection{Description of the bump test conditions}

Used measuring instruments and aids:

- measurement system OKTALON, graphical programing software LabVIEW with measurement algorithms - recording and processing of the measured signal,

- vibration acceleration sensor - ACC-100 $\mathrm{mV} / \mathrm{g}$, fixing - flat magnet,

- impact hammer.

Measurement procedure:

- Calculation of expected excitation force frequencies (operating frequencies values) Tab. 1.

- Preparation of measuring system and vibration measuring aids.

- Choice of united coordinate system - Fig. 2.

- Determination of measuring points, location of sensors, direction and sense of impact Fig. 4, 5 and 6 .

- Measurement at selected measurement locations: vibration acceleration sensor mounting, bump hammer strike near the sensor, vibration acceleration dumping time recording.

- Signal processing: vibration velocity waveform as a result of vibration acceleration time wave integration, FFT vibration velocity time waveform analysis, graphical and tabular processing of dominant frequencies.

- Comparison of bump test results before and after design - Tab. 2. 


\subsection{Measurements results}

Several measurements were performed at different points of the test station supporting structure. Below are the results of selected measurements. At Fig. 4, 5, 6 the location and course of the bump test at selected locations are shown. The direction of sensing the vibration signal and the direction of the modal hammer bump are indicated. After bumping in the indicated direction, the vibrations generated were recorded by a vibration acceleration sensor. Regarding the determination of natural frequencies, it does not matter whether the spectrum is calculated from the ACCELERATION or VELOCITY time course. The frequencies in the spectrum are in the same positions on the " $x$ " axis. The only difference is that VELOCITY is calculated from acceleration by integration. This proportionally amplifies the lower frequencies and suppresses the higher frequencies. Fig. 7, 8, 9 are showns details of frequency analysis of the shock damping time course with the indication of the dominant frequencies obtained from the measurement before test station redesign and the results of a frequency analysis time course of the shock damping after design changes.

- Measurement 1 - Natural frequency measurement of the table with drive mechanism in vertical direction

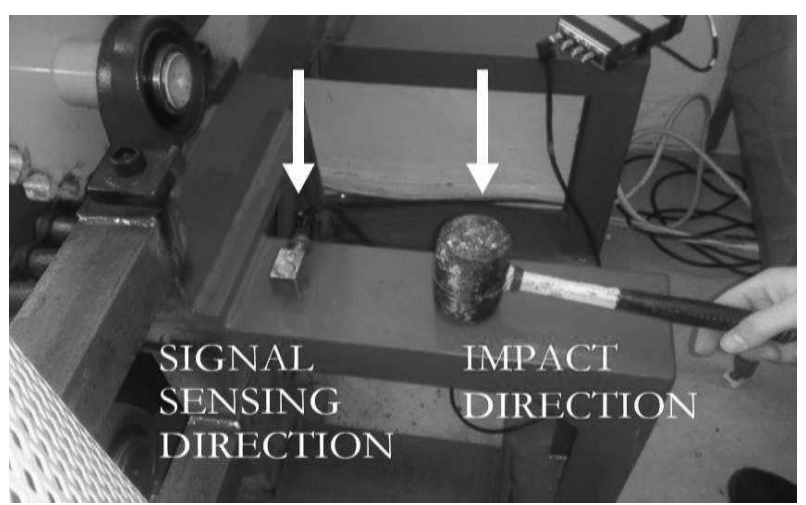

Fig. 4 Measurement 1 - Measurement of the natural frequency of the table in vertical direction
- Measurement 2 - Measurement of natural frequency of vertical frame.

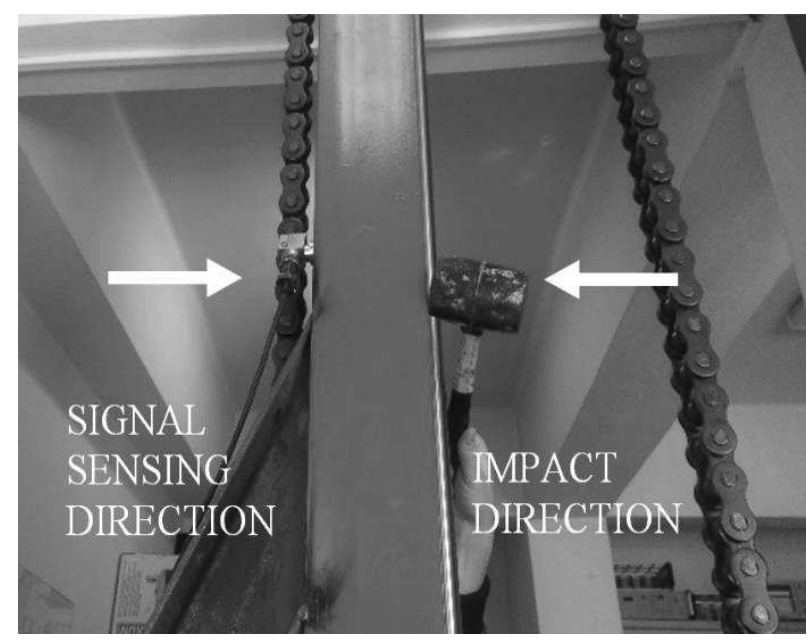

Fig. 5 Measurement 2 - Measurement of natural frequency of the vertical frame

- Measurement 3 - Measurement of the natural frequency of worm gear - horizontally in worms axis direction.

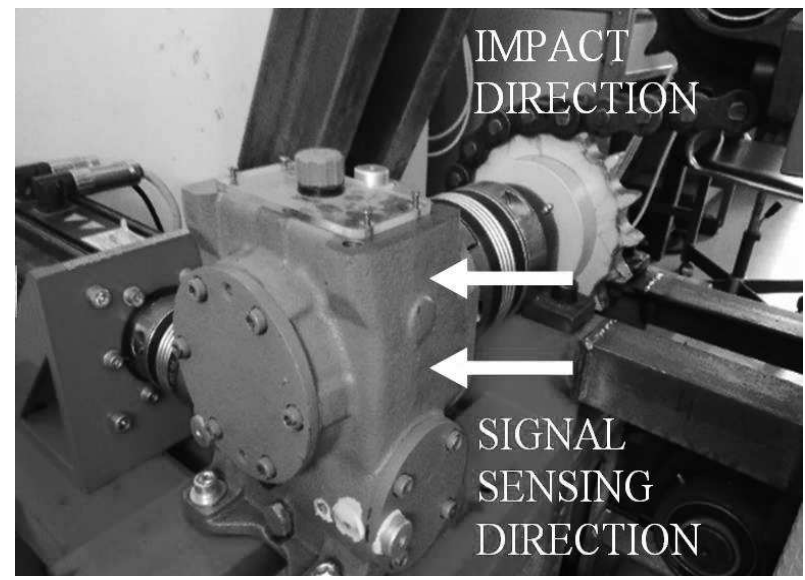

Fig. 6 Measurement 3 - Measurement of gearbox natural frequency in worms axis direction.
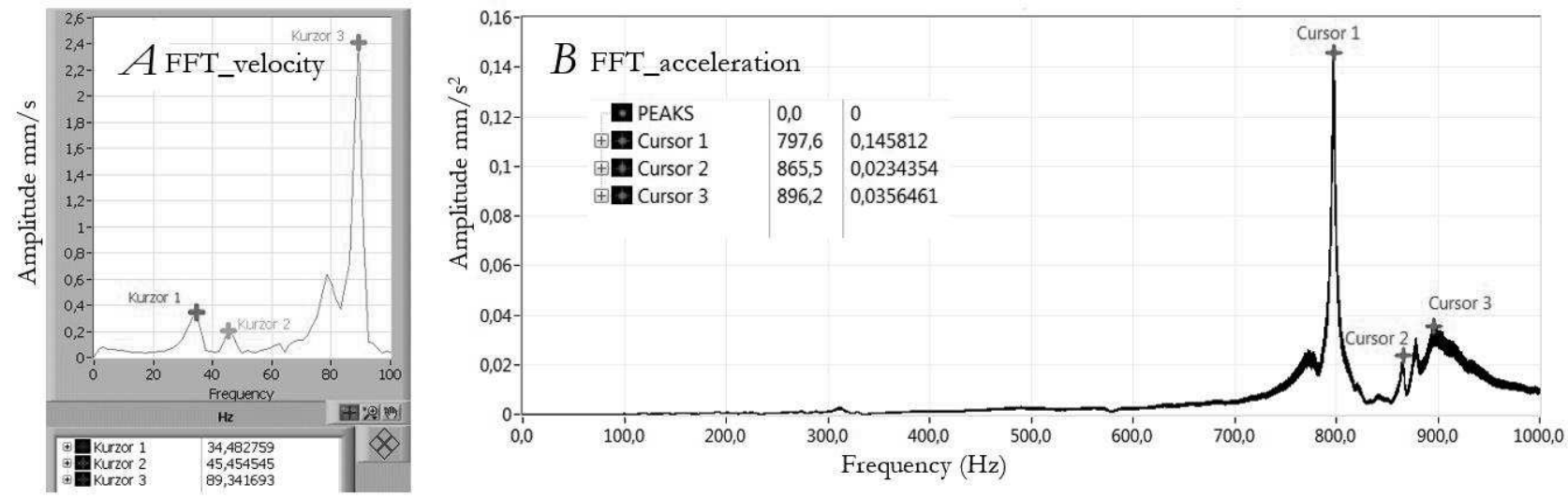

Fig. 7 Measurement $1 A$-frequency spectre before the design change, $B$-frequency spectre after design modification. 

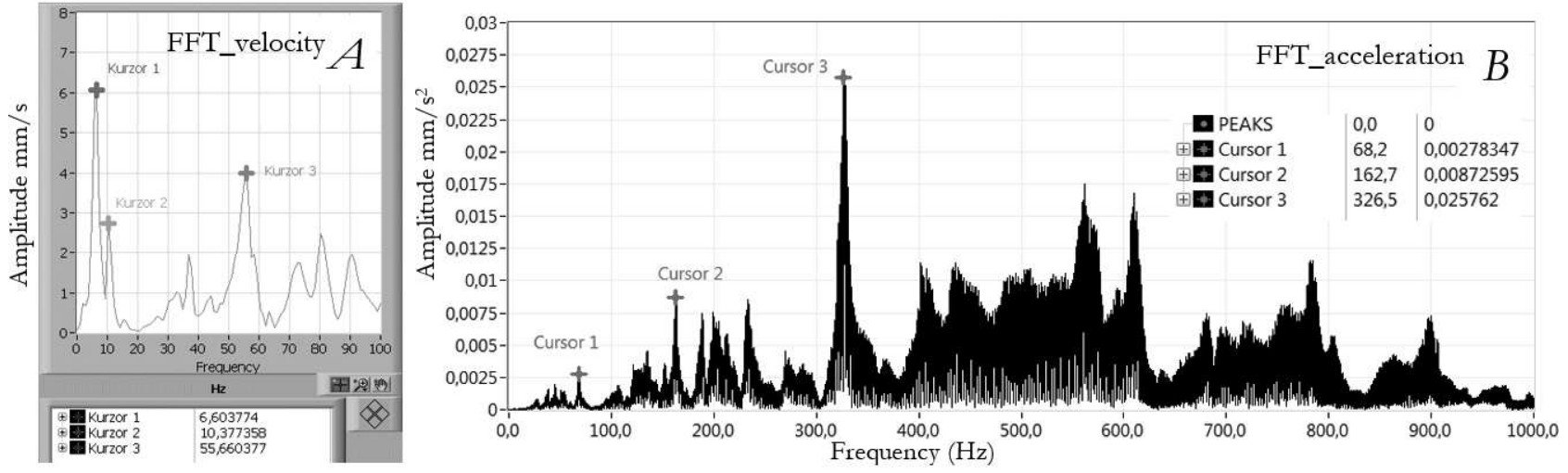

Fig. 8 Measurement $2 A$-frequency spectre before the design change, $B$ - frequency spectre after design modification
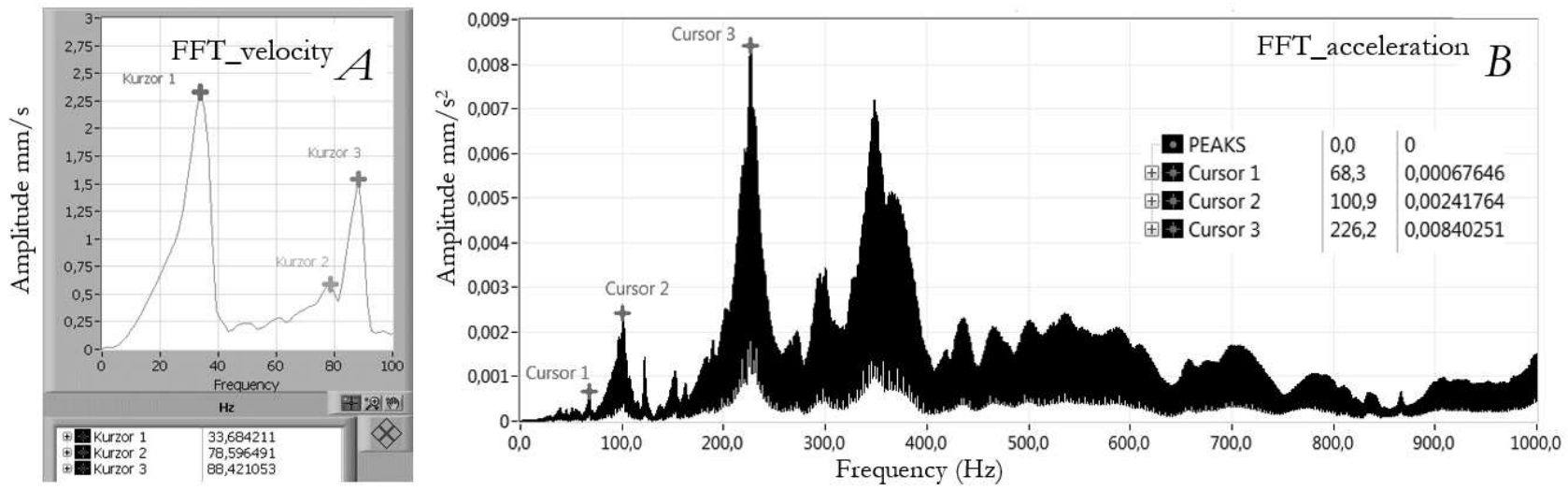

Fig. 9 Measurement $3 A$ - frequency spectre before the design change, B - frequency spectre after design modification

\section{Evaluation of natural frequency measure- ment results}

Repeated impact tests revealed a significant shift in the natural frequencies of the vertical and horizontal beams in the frequency spectrum (see Tab. 2). In the vertical and horizontal direction, there was a significant decrease in the amplitude of the vibration speed after the reinforcement of the frame and a shift of the dominant frequencies far outside the operating values of the frequencies of the excitation forces. For example, in the case of a horizontal table beam, the dominant frequencies have shifted from an area from $30 \mathrm{~Hz}$ to $90 \mathrm{~Hz}$ to an area close to $800 \mathrm{~Hz}$. This creates conditions for obtaining objective results of the planned experimental measurements and for other transmissions and other operating conditions. The natural frequencies of the helical gearbox housing were also measured repeatedly. The shift of the values of the dominant frequencies with significant peaks of the amplitude can be explained as a consequence of the disassembly of the gearbox and its reassembly on the reinforced table.

Tab. 1 Expected frequency - basic calculation

\begin{tabular}{|l|c|c|}
\hline \multirow{2}{*}{ Structural Node } & \multicolumn{2}{|c|}{ Frequency } \\
\cline { 2 - 3 } & Cycles / min & $\mathrm{Hz}$ \\
\hline Engine, input into gearbox, Clutch, Worm & 1400 & 23.3 \\
\hline Output of the Gearbox, Sprocket & 45.16 & 0.753 \\
\hline Transmission chain, frequency of chain links & 768 & 12.80 \\
\hline
\end{tabular}

Tab. 2 Frequencies with dominant vibration values before and after design

\begin{tabular}{|c|c|c|c|}
\hline & \multicolumn{3}{|c|}{ Frequency [Hz] } \\
\hline & Measurement 1 & Measurement 2 & Measurement 3 \\
\hline Condition before design change & $34.5 ; \quad 45.5 ; 89.3$ & $6.6 ; 10.4 ; 55.7$ & $33.7 ; 78.6 ; 88.4$ \\
\hline Condition after design change & $797.6 ; 865.5 ; 896.2$ & $68.2 ; 162.7 ; 326.59$ & $68.3 ; 100.9 ; 226.2$ \\
\hline
\end{tabular}




\section{Conclusions}

Vibration diagnostics belongs to modern methods of non-destructive technical diagnostics, by means of which it is possible to determine the current technical state of various production machines and equipment directly in the process of operation. The use of methods of vibration diagnostics is the basis of experimental tests of dynamic properties of gears. A test station was designed and built for the implementation of experiments. Verification tests proved the shortcomings of the stend. The main shortcoming of the original design were significant resonance events. The aim of the design modifications of the testing station for dynamic testing of toothed and belt drives was to eliminate the danger of resonance and increase the stiffness of the basic stend structure. A bump test performed under the same conditions before and after frame reinforcement confirmed that by the structural modification of the testing facility was achieved a higher rigidity of the base frame. Shifting the natural frequencies, especially of the vertical and horizontal beam, outside the operating frequencies of the tested transmissions is a necessary condition for achieving objective results of the planned experiments.

\section{Acknowledgement}

This work was supported by the Slovak Research and Development Agency under contract no. APVV-18-0316.

\section{References}

[1] ŠMERINGAIOVÁ, A., VOJTKO, I., MONKOVÁ, K. (2015). Experimentelle Analyse der Dynamik von Zahnradgetrieben - Teil 1. tm-Technisches Messen, Vol. 82, No. 2, pp. 57 64.

[2] PAVLENKO, S., MAŠČENÍK, J., KRENICKÝ, T. (2018). Worm gears: general information, calculations, dynamics and reliability, p. 167. Lüdenscheid: RAM-Verlag. ISBN 978-3942303804

[3] ŠMERINGAIOVÁ, A., VOJTKO, I., MONKOVÁ, K. (2015). Experimentelle Analyse der Dynamik von Zahnradgetrieben - Teil 2. In: tm-Technisches Messen, Vol. 82, No. 4, pp. $224-232$.

[4] ISO 10816-3:2009 Mechanical vibration. Evaluation of machine vibration by measurements on non-rotating parts - part 3
[5] MURČINKOVÁ, Z., MURČINKO, J., ADAMČÍK. P. (2016). The multi-parameter on-line monitoring system applied for rotating machinery. In: Review of Industrial Engineering Letters, Vol. 3, No. 2, pp. 19-28.

[6] OLEJÁROVÁ, Š., RUŽBARSKÝ, J., KRENICKÝ, T. (2019). Vibrations in the Production: System Measurement and Analysis with Water Jet Technology. 1rd ed. Cham: Springer Nature Switzerland.

[7] ŽIARAN, S. (2016). Low frequency noise and vibration (Nį̌kofrekveníny bluk a kmitanie), p. 316. STU Bratislava. ISBN 9788022745369

[8] ZÁHOREC, O., CABAN, S. (2002). Dynamics (Dynamika), p. 500. SjF TUKE Košice. ISBN 80-7099-825-3

[9] ÇAKAR, O. (2018). A method for shifting natural frequencies of a dynamic system to desired values with concentrated mass modifications. In: Journal of Vibroengineering, Vol. 20, No. 1, pp. 1- 12.

[10] KALIŃSKI, K. J. et al. (2019). Optimization of the spindle speed during milling of large-sized structures with the use of technique of Experiment-Aided Virtual Prototyping. In: Applicable Solutions in Non-Linear Dynamical Systems: Proceedings of the DSTA 2019, pp. 249-58. Lódź: Politechnika Łódzska.

[11] KLIMENDA, F., SOUKUP, J., STERBA, J. (2019). Noise and Vibration Analysis of Conveyor Belt. In: Manufacturing Technology, Vol. 19, No. 4, pp. 604-608. Elsevier. Netherlands.

[12] LIU, SY. et al. (2019) Investigation on the influence of work holding equipment errors on contact characteristics of face-hobbed hypoid gear. In: Mechanism and Machine Theory, Vol. 138, pp. 95-111.

[13] MO S., ZHANG T. (2020). Analytical Investigation on Load Sharing Characteristics of Herringbone Planetary Gear Train with Flexible Support and Floating Sun Gear. In: Mechanism and Machine Theory, Vol. 144, No. 2, pp. 1-27.

[14] VAŠINA M., HRUŽÍK L., BUREČEK A. (2020). Study of Factors Affecting Vibration Damping Properties of Multilayer Composite Structures. In: Manufacturing Technology, Vol. 20, No. 1, pp. 104-109. 